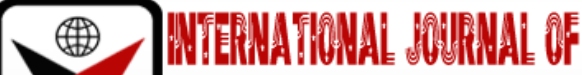 \\ בmRक
}

ISSN 2278 - 0211 (Online)

\section{Thematic Analysis of Appellations among the Tongu-Ewes of the Volta Region of Ghana: The Case of Agave Traditional Area}

\author{
Clever Susuawu \\ Tutor, Department of Languages, Peki College of Education, Ghana
}

\begin{abstract}
:
This study focuses on the thematic analysis of appellations among the Tongu-Ewe of the Volta Region of Ghana: the case of Agave Traditional Area. The study indicates that themes are important and central to the study of appellations because the audiences are interested in knowing the central ideas in the text. The study lays emphasis on the notion that the audience are interested because appellations are also maxims, philosophies or principles that guide the life of individuals in the society. It was revealed that most of the themes are based on life situations such as truth, love, honesty, struggle, hatred, violence and all other virtues and vices of life. It has been noticed that most of the motifs or themes evolve from political, economic, religious and social life of the people. The understanding of themes in appellations can only be realized when the stem and its explanation or justification is considered and analysed as most of the themes are inherent. It was indicated that appellations are performed orally through dialogue. This aspect of appellation performance is mostly ignored by the society. The fact was established that dialogue is important in the rendering of the genre in several ways. Dialogue helps to reveal the theme and characters in the text and thus raises the emotions of renderers and audience for the understanding of the message. Through the dialogue, the social status of the renderers and their diction is revealed. The researcher adopted interview as a tool for his research. He concentrated on clan heads, family heads and those who are knowledgeable in this field to solicit his information on thematic appellations. From the findings of the study, one can infer that the environment has tremendous influence on the life of the citizens of Tongu-Ewe. In the light of this, it is being suggested that the citizens must be sensitized to embrace and support the states policy on environmental protection so as to preserve and sustain the composition and the use of appellations. It was established that appellations are a potent force for the resolution of conflicts in order to ensure peace and stability in the society. In line with this revelation, it is useful to suggest that the mere inclusion of the genre in the Ghanaian languages curriculum is not enough. Policy makers must ensure the effective teaching and learning of not only appellations but also the other oral arts in order for them to achieve their educational objectives.
\end{abstract}

Keywords: Thematic,analysis, appellation, manipulated, communication, compositions

\section{Introduction}

One of the main causes of the absence of scholarly interest in the oral arts in Africa, in the main, is incipient in nineteenth-century views and perceptions of Africa as a cultural and imaginative artistic area. For several years after the turn of the century the idea of "oral" literature sounded bizarre and grotesque in the ears of some European and African educationists who exercised influence on the form and content of academic curricula. To such influential men and women creative literature consisted of objects which either appeared in print or whose authorship could be attributed to identifiable individuals.

All other literary compositions expressed orally were artistically crude and, at best, simple, and were interesting only in so far as they were some of man's mental creations designed to serve practical or specified social functions. Such pieces, it was held, were products of a communal psyche and had no authors. Their worth was to be judged in relation to the highly imaginative pieces of writing in European languages taught in our universities.

In spite of advances in African Studies as a scholarly sub-field in the humanities, oral literature continued to suffer some of the worst prejudices of Darwinist and other evolutionist theories of development.

According to these perceptions, imaginative compositions which were realized orally were at primitive stages of development. These and similar ideas of the nineteenth century were, of course, speculative. Nevertheless, they were given scientific validation by the theory of evolution.

The impressions appellations make on their perceptions demonstrate their desires to won or disown them. Appellations as aesthetic tools impact greatly on the life of individuals, families, clans and the community. 


\section{Statement of the Problem}

There has been series of studies in the literature regarding appellations: however, this research is to analyze the various themes of appellations among the Ewe of Agave Traditional Area.

\section{Research Questions}

- What are the various themes of appellations among the Ewe of Agave Traditional Area?

- What are the usefulness of the classifications of appellations into themes?

\section{Purpose of the Study}

The purpose of this study is to analyze the various themes of appellations among the Ewe of Agave Traditional Area.

\section{Review of Related Literature}

Appellations, indeed, are sources of pleasure and satisfaction because they are sublime, beautiful and useful. They stimulate and soothe people, teach, encourage people for strenuous work and invigorate people's spirits. Appellations help in the renewal of people's spirits, executing, giving courage and enthusiasm to people for strenuous work. They help create a social bond between individuals and groups by arousing sympathy, understanding and the desire for harmonious relationships. The aesthetic experiences that are demonstrated through moods and attitudes can be thus summed up in one word, beauty. Every artistic work has beauty inextricably attached to it.

The question of what constitutes oral literature is a complex one. It perhaps calls for a very clear understanding of the principles that govern the people's appreciation of their own creative verbal art, (Okombo, 1992:22). The interpretation of this is that what constitutes an artistic or creative utterance in any one culture or situation is not a constant variable, nor does it subscribe to a constant criterion. Despite this, Okombo (ibid) recommends Benson and Hughes' "ethno methodological approach" as a possible route to finding out what merits being art in a given culture. He explains the approach as based on the recognition by social scientists of the fact that human communities are not just communities of naïve actors; they are also communities of analysts, who reflect and pass judgments on their own actions. The work of the individual members of a community is on the whole directed by their own consciousness of the judgmental expectations of their community (P.22).

Each community has a yardstick, though tacit, upon which to judge their own art. We may say that it is by this yardstick that the people will be able to say that this artist is better than the other, or that, that performance was well done and that, this dance or that song is truly our own. Indeed this view finds support from Leo Tolstoy's (1988:82) justification of such separation when he says: "it is necessary for a society from which works of art arise and are supported to find out whether all that professes to be art is really art." This recognition seems to demand of us to take extra caution before declaring an utterance as oral literature.

\section{Methodology}

The researcher informed the clan leaders, family heads, and those who have in-depth knowledge in appellation that he needed to interview them about issues concerning appellation. The researcher met the various leaders and gave them the time schedule for the appellation. As tradition and custom demands, the researcher offered the required drinks to the various leaders and few members of the clan and family respectively. These clan heads, family heads and those who are knowledgeable in this field took the researcher through series of thematic appellations. The researcher was briefed on when and where these appellations are appropriately used. The respondents requested that the researcher provide the necessary appellation resources such as: water, cloth, calabash, drum, drink (akpeteshie, palm wine, and other traditional herbs. The day was set for the performance.

I collected the data in this paper from the Ewe communities (especially from the Volta Region) in 2018. Most of the data were collected in natural encounters by participant observation. Few clan leaders gathered and the ceremony stated. The resource person in charge of appellation welcome the members from the society and indicated to the gathering that appellation have different importance and various occasions where they usually take place. After briefing the gathering about the purpose of the gathering, the resource person started the appellation process. The resource person gave appellations based on the various themes of appellation such as: Appellations Performed Orally through Dialogue and Appellations on the Drum and with the Horn. The various occasions by which appellations are performed orally were demonstrated. Similarly, the ceremonies that required the appellation of the Drum and with the Horn were also exemplified. The researcher took notes and recordings of ceremony. The ceremony lasted about two hours and the researcher expressed his satisfaction to the gathering and assured the resource persons that the information they have provided would be kept confidential.

\section{Discussion}

Scholars of Ewe appellations, unlike Finnegan (1970) failed to study themes of the genre. Themes are important and central to the study of appellations because the audiences are interested in knowing the central ideas in the text. They are interested because appellations are also maxims, philosophies or principles that guide the life of individuals. Most of the themes are based on life situations such as truth, love, honesty, struggle, hatred, violence and all other virtues and vices of life. Most of the motifs or themes evolve from political, economic, religious and social life of the people. The understanding of themes in appellations can be only be realized when the stem and its explanation or justification is 
considered and analysed because most of the themes are inherent. Two examples worthy of note in this regard are the following.

- A3ayiga: Wome5oa a3aw43u dzro o, gake le dzidz4kp4kp4 sub4sub4 me la wo5oa3u,

Translation: War drums are reluctantly beaten but it is a thing of joy to beat drums of worship.

The theme of this appellation is appreciating the difficulty that goes with a particular task and the easiness that accompanies other similar tasks.

- Ahosi2ela mev4na "4li o. Enya be ye kpleamekukulae le ahosia mam,

The meaning is that, he who marries a widow should not be afraid of a ghost because the one is aware that he is sharing the woman with a dead man. The theme is that risk-taking and its consequences are a fact of life. In other words, if you wish for war, you have it.

It is clear that the themes of appellations emerge from common experiences. Access to them pose no problems at all for users for most of the themes are implied being insights into life or human nature.

\subsection{Appellations Performed Orally through Dialogue}

An aspect of appellation performance which is mostly ignored is the use of dialogue. A dialogue is a socio-linguistic phenomenon. Its use dominates almost all daily discourse in any given society. It involves two or more people in partnership in a chat. It is a social situation in which there are speakers and listeners, all of whom share in a language common to them. In a dialogue, ideas are exchanged to the satisfaction or dissatisfaction of both speakers and listeners. In fiction, non-fiction and drama, dialogue is used to create scenes. The researcher was an eyewitness of appellation performance through dialogue. It is reported here as a way of illustrating the dialogue between two intimate friends who after several years of separation met once again.

Agblegodoe: (Recites his friend, Katakogako's appellation)

Katakogako! A2a3at4tsitsi be

Katakogako! Lunaticold says

Yelé da kple asi

He caught snake with the hand

Wogbl4e wòbeyeléekoyelée

When advised he said (once) he has caught it he has caught it.

Katakogako: (Responses and recites Agblegodoe's appellation)

Ago!NyeGbeleawo 5e `utsuvi

(Response)I Gbeleawo (clan name)'s son

Agblegodoe! Ebeyelihafi `4ny4 4wodzo:

Agblegodoe! He says he existed before the beautiful went

Eye yegalihafi “4ny4`4ny4wo dzo.

And he was (still) there before the beautiful ones departed

The meanings of the two appellations are as follows:

- Katakogako, the old lunatic, proclaims that once he grabs a snake, he grabs it; there is no (need) letting it go or freeing it. It is unwise to spare one's enemy.

- Agblegodoe (Farming attire) says he had been in existence before the new farming attire arrived and he will continue to be when the new ones depart. In life nothing is useless.

The drama of the exchanges ended up in handshakes, the sharing of drinks and ideas. In Tongu, appellations are an indispensable appellations which precede the dialogue. The rendering of the texts interject the conversation that goes on and other rendering sums up and seals the exchanges. The delivery of appellations in itself entails coding and decoding. The genres exchanged are the messages which both speakers and listeners interpret for meaning and reaction.

The rendering takes place at a 'stage' and in time. Usually, there is audience witnessing the performance. Dialogue is important in the rendering of the genre in several ways. Dialogue helps to reveal the theme and characters in the text and thus raise the emotions of renderers and audience for the understanding of the message. Through the dialogue, the social status of the renderers and their diction is revealed. The oral skills of the renderers add pleasure or displeasure to the whole episode. The use of dialogue in the performance of appellations demonstrates the orderly packaging and presentation of the genre as an acceptable social and linguistic norm. One TsatsuAdzrolo, a citizen of Tongu, observes that "when appellations are performed through the medium of dialogue, the audience enjoy the fluency of the exchanges, voice modulation and the entire episode.

Speakers in the action try to show articulatory brilliance, with and at the same time try to outwit the other according to the appellations borne by the two contestants. The solemnity, dignity, self-confidence, and courtesy in the delivery. The speakers' language use and action evoke the audience's admiration. Through the language of the people engaged in an appellation dialogue, the audience see meaning enacted as well as expressed. The verbal dimension of the dialogue used is reinforced by action, gesture and movement.

What has just been described concerning dialogue confirms what communication theorists such as Jacobson and Todorov have postulated. These theorists identified phenomena such as graphic representations of the interactions of variables-sender, receiver, message, medium, code and feedback. The scholars note that communication's intention is to inform, instruct, persuade and to entertain. Additionally, communication shows surveillance, correlation, socialization, personal identity, social integration and cognition. Above all, it incorporates politeness, respect and the rule of considerations. 
From the exposition on the use of dialogue, the researcher observed that appellations reveals character, advances action and establishes the setting of episodes. Amega Akpla Wotuinawo, an elder of Avuto, remarked that 'the recitation of any appellation between two people or groups of people is a kind of social dialogue. If the delivery does not take place in the framework of dialogue, its beauty is lost and does not shine'.

\subsection{Appellations on the Drum and with the Horn}

Appellations are performed on the drum and in horn language. The researcher's eyewitness account is presented here. Two atumpani drums, male and female, were mounted. The chief drummer was then invited to perform an appellation of the chief on them. He first removed his sandals, made bare his chest by lowering his cloth on his shoulder and knotted the cloth on his chest with the rest hanging downwards towards his heel; the knotted portion overlooking like a watchtower. He walked majestically towards the chief and his elders and bowed before them, signifying that he paid reverence and sought permission to perform.

He then walked towards the drums, picked two fork-sticks. He held one in his left hand and the other in his right hand. He then positioned himself in-between the two drums. The drummer raised his head towards heaven together with his hands. After lowering both hands and arms, he turned again in the direction of the chief and elders and bowed his head signifying that he was ready to perform. He struck three beats of three in succession testing the potency and readiness of the drums and as a warm-up. In this first instance, the drummer played and 'recited' the following on the drum" Gazu bomel7 o! Gazu bomel7 o! Ayi t45e agble n45e 2i o. Gazu bomel7 o!

Translation: Be not a nuisance! Be not a fool! Be not a vagabond deserting your patrilineal for matrilineal! Be not a nuisance! The appellation text tries to explain its stem, 'bomel7' further. Bomel7 literally means a fool of destiny, a perpetual fool. The appellation is cautioning someone not to be naturally foolish. This kind of foolishness is explained by the words "Ayi t45e, agble n45e 2i o", meaning one should not abandon his patrilineal which is the more important in patrilineal societies such as the Ewes. Enjoying the treasurers and pleasures of a matrilineal may be expedient; but eventually, there is no heritage there for the individual. The appellation implies further that the wise thing to do is to keep one's patrilineal where there is inheritance of position and property. A double standard life can be detrimental to one's future development.

The appellation casts insinuation and alludes to enhancing one's social status by taking wise decisions. The linear repetition as shown in the words "Gazu bomel7 o!, meaning in once sense "be not a nuisance" and in the other "be not a fool or vagabond", explains the intensity and degree of protest against double standards. Causing confusion and embarrassment to oneself is tragic. The appellation which was metaphorically expressed was an advice.

As the drummer played the appellation, the chief's spokesman and some eminent elders raised their right arms and made a victory sign. At the end of it all, the chief and his retinue rose in honour and commemoration of the appellation because its message was well understood.

In the second instance, one of the elders of the chief volunteered to recite an appellation for the drummer to strike its message. As he recited and the drummer performed, the audience nodded their heads in approval. The researcher saw some of the members of the audience tapping their feet to the rhythm of the drum. In the end, both men were congratulated. While the elder took his seat, the drummer hanged the sticks on the drum.

The horn-blower had his turn. Unlike the drummer, he knotted his cloth at the back of his neck. The cloth then made a long journey to his heel and stopped at the heel. He similarly went through the ritual formalities of greeting, seeking permission and honouring the chief and the Almighty God. He held the ivory horn with his right hand. He cleared his throat and began to blow the tune of the following appellation. Vetete (teti) 2oa tsy-a! Vetete 2oa tsy-a! Vetete 2oa tsy-a! Atsy-a! Atsy-a! Atsy$\mathrm{a}$ !

Translation: Ewe triumph!? Triumph and triumph!? Victory! Victory! Victory! For Ewes?

The root word of this appellation is Ewe. The name refers to the Ewe-speaking people. Other ethnic groups usually undermine the military power of the Ewes but respect them for their truthfulness, honesty and hard-work. The appellation tries to project the positive achievement of the Ewes. The people won a war which was not described in the text. The announcement of victory in this particular encounter was intriguing.

The importance of the appellation lies in the phrase. Vetete' meaning 'Ewes also". The phrase implies that the victory of the people over their enemy was least expected. "Victory" depicted in the word 'asty-a' also meaning 'beauty' come, therefore, as a surprise. The unexpected victory must resound repetitively for people to understand it as a central message of the appellation. The message is expressed in a rhetoric question which is not meant to be answered; but rather the victory must be appreciated and celebrated. The appellation is honorific and praise-worthy.

The horn-blower manipulated the streams of air, controlled and modulated the rhythm and tonality of the genre through intermittent release. As this air release was going on, he used his thumb, fore and middle finger in controlling also the air waves. These activities created in the rhythm and tonality of the appellation pleasure and beauty. At the end, the horn blower performed the concluding rituals. He hanged the horn around his neck. The reaction of the audience was similar to that of the drum performance.

The discussions indicate that the Tongu-Ewes' concept of appellations is not about drinking per se but rather, it is more about social relations particularly among peer groups. That the beauty and values as well as the richness of social relations and interactions are seen through sources, nature, themes, classification, linguistic and literary merits and delivery of appellations. It is only through the above-mentioned means that the significance of the genre can be appreciated and its future defended. 


\section{Conclusions and Recommendations}

From the findings of the study, the environment has tremendous influence on the life of the Tongu-Ewe. It is, therefore, indispensable particularly in the production of appellations. In the light of this, it is being suggested that the people must be sensitized to embrace and support the states policy on environmental protection so as to preserve and sustain the composition and use of appellations. It was stated that appellationsare performed orally through dialogue while other appellations are performed on the drum and with the horn,In addition, appellations are a potent force for the resolution of conflicts in order to ensure peace and stability in the society. In line with this statement, it is useful to suggest that the mere inclusion of the genre in the Ghanaian languages curriculum is not enough. Policy makers must ensure the effective teaching and learning of not only appellations but also the other oral arts in order for them to achieve their educational objectives. Teachers and other educationist must be encouraged and supported to teach them for entertainment, communication, philosophy of traditional education and ethics. The youth, in particularly, must be encouraged to learn and appreciate the ethical and aesthetic lessons of the genre to enable them to learn to overcome the temptations that lead them to involve in acts of indiscipline, crime and shameful conduct.

Again, it is being suggested that researchers resourced and financed to undertake research intensively and extensively in the oral arts in order to produce the future scholars of the language.

\section{References}

i. Finnegan, Ruth. (1970). Oral literature in Africa. London: Oxford University Press.

ii. Okombo, 0. (1992). "The Place of Ethno Methodology in the Study of Oral Literature." In ReflectionsonTheories and Methods in Oral Literature, (eds) Okombo, 0. And J. Nandwa. Nairobi: Kola.

iii. Tyson, Lois. (2006). Critical Theory Today: A User Friendly Guide, 2 nd Edition. New York: 